\title{
ОПЕРАТИВНЫЙ И ПРЕВЕНТИВНЫЙ ИНСТРУМЕНТАРИЙ РЕАЛИЗАЦИИ ВНУТРЕННЕГО ФИНАНСОВОГО КОНТРОЛЯ В РАМКАХ РАСХОДОВАНИЯ СРЕДСТВ НА ФЕДЕРАЛЬНЫЕ ПРОЕКТЫ
}

\author{
(c) 2020 Петров Александр Михайлович \\ доктор экономических наук, профессор Департамента учета, анализа и аудита \\ Финансовый университет при Правительстве Российской Федерации, Россия, Москва \\ E-mail: palmi@inbox.ru
}

При усложнении рыночной конкуренции, усугублении кризисных ситуаций, нестабильности и неопределенности влияния различных факторов необходим четкий контроль, позволяющий выявить основные причины разбалансированности отдельных субъектов финансовой системы и бюджетного процесса для разработки более эффективных механизмов для их устранения. Реализация данной задачи предполагает усиление требований к финансовому контролю, а также совершенствование механизмов и инструментов его реализации как с позиции распределителей бюджетных средств, так и их получателей. Практика свидетельствует, что более эффективным и экономичным является не устранение последствий нарушений, а их своевременное выявление и предотвращение. Таким образом, совершенствование инструментария финансового контроля должно основываться на оперативном и превентивном подходах.

Ключевые слова: задачи, инструментарий, контроль, кризисные ситуации, механизмы, подходы, проекты, расходы, реализация, средства, финансы, экономическая информация, эффективность.

В настоящее время контроль занимает главенствующее место как на микро-, так и на макроуровнях. В общем виде контроль независимо от уровней разделяется на внешний и внутренний.

Внешний контроль выполняется внешними специализированными органами или субъектами в рамках исполнения профессиональных функций и обязанностей.

Внутренний контроль реализуется внутри экономических субъектов, штатными сотрудниками (внутренними контролерами, внутренними аудиторами).

Ключевая функция внутреннего контроля состоит в разработке и представлении не только предложений по ликвидации выявленных нарушений, но и рекомендаций по росту эффективности управления, изысканию резервов развития.

Внутренний контроль является важной функцией управления, охватывающей учет, финансовый анализ, сравнение и оценку фактически достигнутого результата с установленными целями и задачами отдельного экономического субъекта или государства в целом.

Внутренний контроль является процессом проверки, который организуется хозяйствую- щим субъектом для обеспечения реализации всех управленческих решений в области финансовой деятельности для достижения стратегических целей и предупреждения кризисных ситуаций, правонарушений.

В настоящее время существует множество подходов к раскрытию сущности внутреннего контроля, что свидетельствует о сложности данного процесса и его развитии на протяжении долгого периода. Концептуальные основы внутреннего контроля в работах российских ученых позволяют определить его как подсистему управления организацией, ориентированную на результат управления финансами посредством инструментов контроля, с целью обеспечения непрерывного потока внутренней и внешней информацией для разработки и принятия обоснованных управленческих решений.

Внутренний контроль необходимо рассматривать как парадигму управления финансами и как систему взаимосвязанных между собой и внешней средой во времени и пространстве элементов, образующих единое целое для осуществления стратегических и тактических задач.

Эффективность системы финансового управления определяется качеством применяемого инструментария, оперативностью и пол- 
нотой информационного обслуживания заинтересованных пользователей, квалификацией финансовых кадров, менеджеров и системой внутреннего контроля.

Основные элементы внутреннего контроля описаны в Информации Минфина России N П3-11/2013 «Организация и осуществление экономическим субъектом внутреннего контроля совершаемых фактов хозяйственной жизни, ведения бухгалтерского учета и составления бухгалтерской (финансовой) отчетности» [1]. Представим их на рисунке 1 и раскроем содержание каждого.

Контрольная среда характеризуется совокупностью принципов и стандартов функционирования организации, которые устанавливают единое понимание внутреннего контроля и требования к внутреннему контролю. Контрольная среда характеризует культуру управления и формирует надлежащие отношение кадров к построению и реализации внутреннего контроля.

Оценка рисков является процессом по определению и анализу рисков. При этом под риском принято понимать сочетание вероятности и последствий недостижения организацией своих целей деятельности.

Процедуры внутреннего контроля - это действия, которые направлены на снижение рисков, влияющих на достижение организацией своих целей.

Своевременная и достоверная информация направлена на обеспечение внутреннего кон- троля и достижение им поставленных целей и задач. Основным источником информации для внутреннего контроля являются информационные системы экономического субъекта.

Коммуникация - это распространение информации, требуемой для разработки и принятия управленческих решений, а также реализации внутреннего контроля.

Оценка внутреннего контроля осуществляется в рамках вышеперечисленных элементов для установления их эффективности и результативности, а также в случае необходимости их корректировки.

Роль финансового контроля повышается с каждым днем не только в деятельности отдельной организации, но и государства в целом.

По своей сути финансовый контроль имеет широкий спектр применения, считаем, что необходимо расширить основные его элементы. Представим их на рисунке 2.

Система финансового контроля Российской Федерации состоит из государственного (муниципального) и негосударственного финансового контроля, каждый из которых подразделяется на определенные подсистемы (рисунок 3).

Согласно статьи 265 Бюджетного кодекса Российской Федерации (БК РФ) «государственный (муниципальный) финансовый контроль осуществляется в целях обеспечения соблюдения положений правовых актов, регулирующих бюджетные правоотношения, правовых актов, обусловливающих публичные нормативные

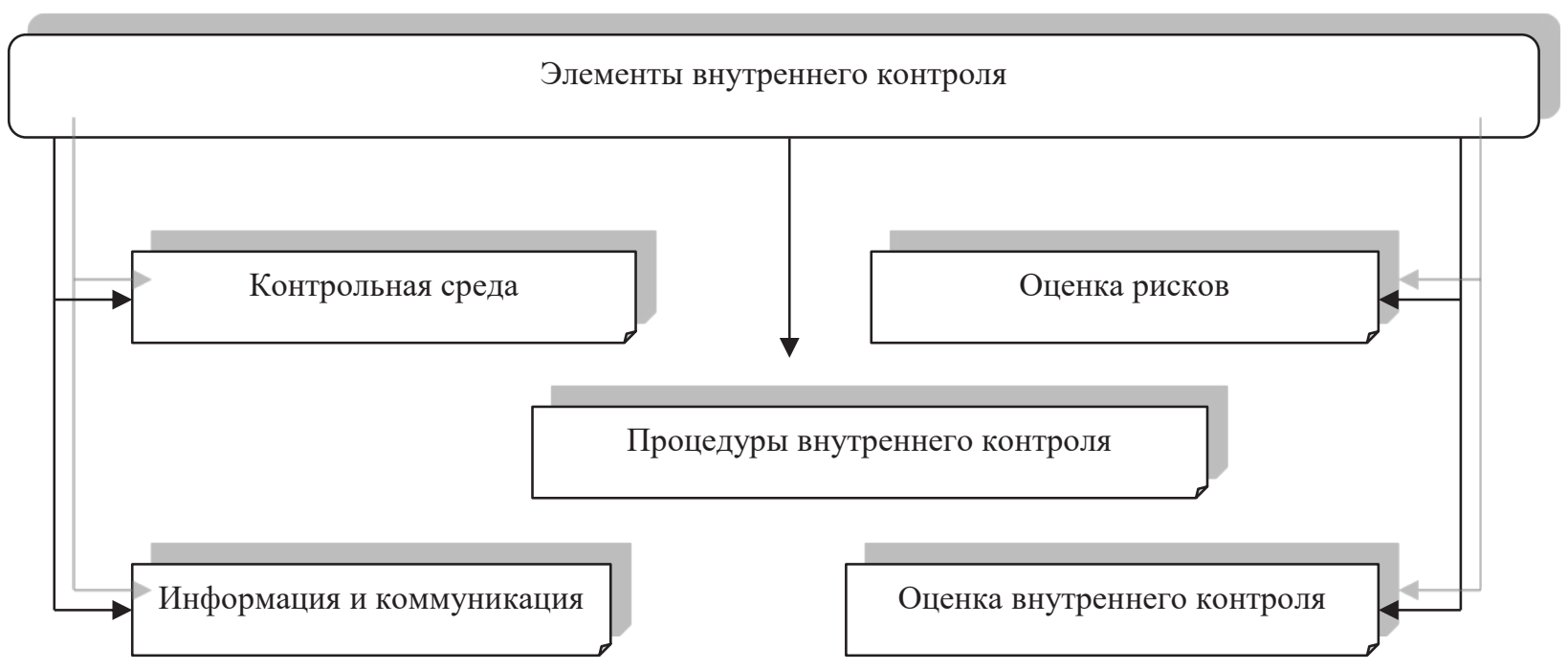

Рuc. 1. Элементы внутреннего контроля 


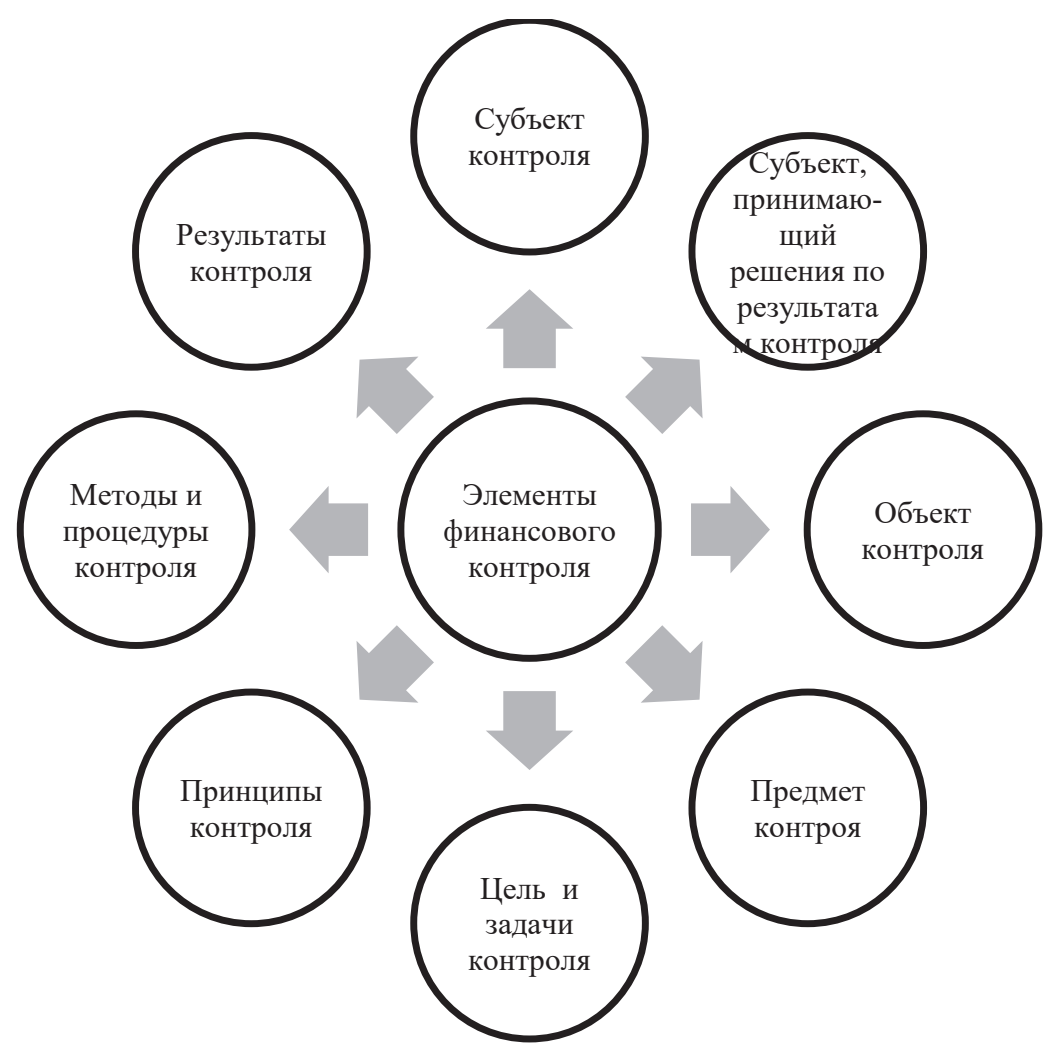

Puc. 2. Расширенные элементы финансового контроля

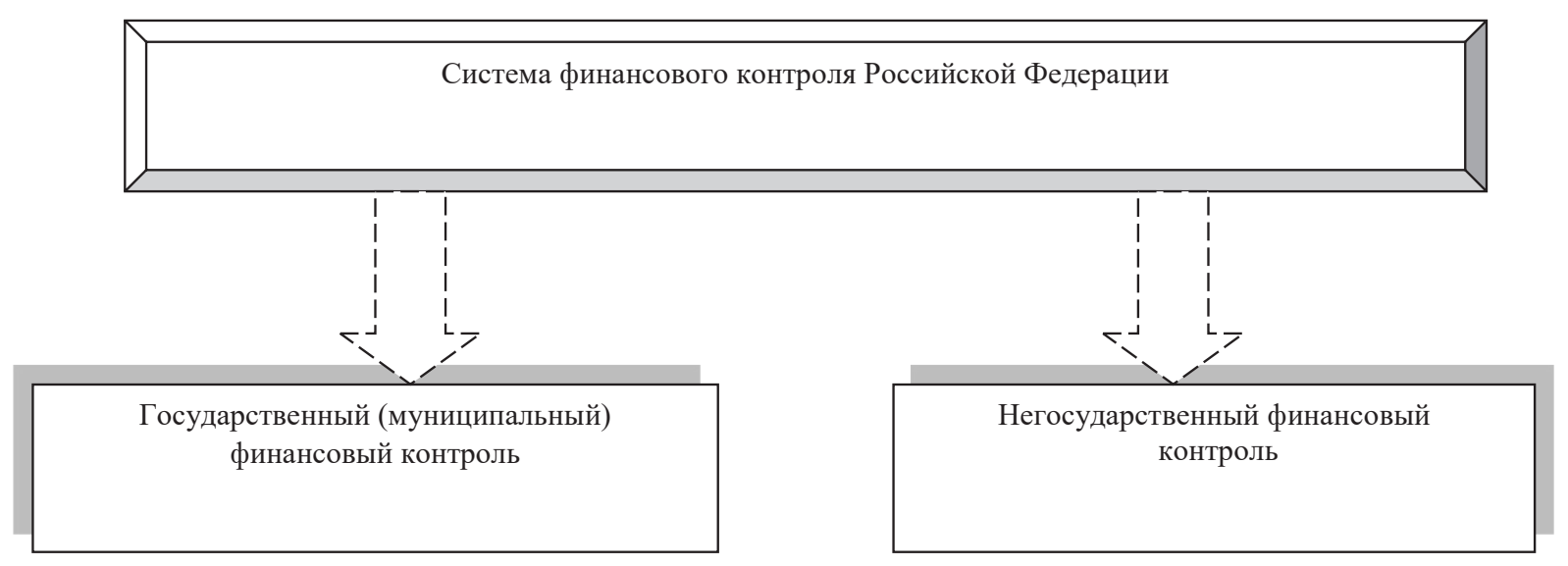

Рис. 3. Система финансового контроля Российской Федерации 
обязательства и обязательства по иным выплатам физическим лицам из бюджетов бюджетной системы Российской Федерации, а также соблюдения условий государственных (муниципальных) контрактов, договоров (соглашений) о предоставлении средств из бюджета» [2].

Государственный (муниципальный) финансовый контроль подразделяется на внешний и внутренний, предварительный и последующий (рисунок 4).

Основной составляющей государственного управления выступает государственный финансовый контроль. При выполнении ключевых целей и задач государство выделяет бюджетные средства на реализацию федеральных проектов.

Следовательно, можно выделить основные задачи государственного финансового контроля в рамках расходования средств на федеральные проекты.

K важнейшей задаче государственного финансового контроля относится формирование инструментария и системы информации, позволяющих прослеживать весь процесс исполнения таких проектов на всех этапах и дающих основу для разработки и принятия экономически оправданных управленческих решений. Именно по результатам оценки установленных отклонений фактических показателей от плановых или технического задания по федеральным проектам можно выявить несоответствия, нарушения.

Отсюда следует, что ко второй важнейшей задаче государственного финансового контроля относится сбор и систематизация информации о расходовании бюджетных средств на предмет:

- законности;

- целесообразности;

- целевой направленности;

- эффективности.

Третья задача государственного финансового контроля направлена на выявление соразмерности бюджетных расходов с целями и задачами государства, которые решаются в рамках

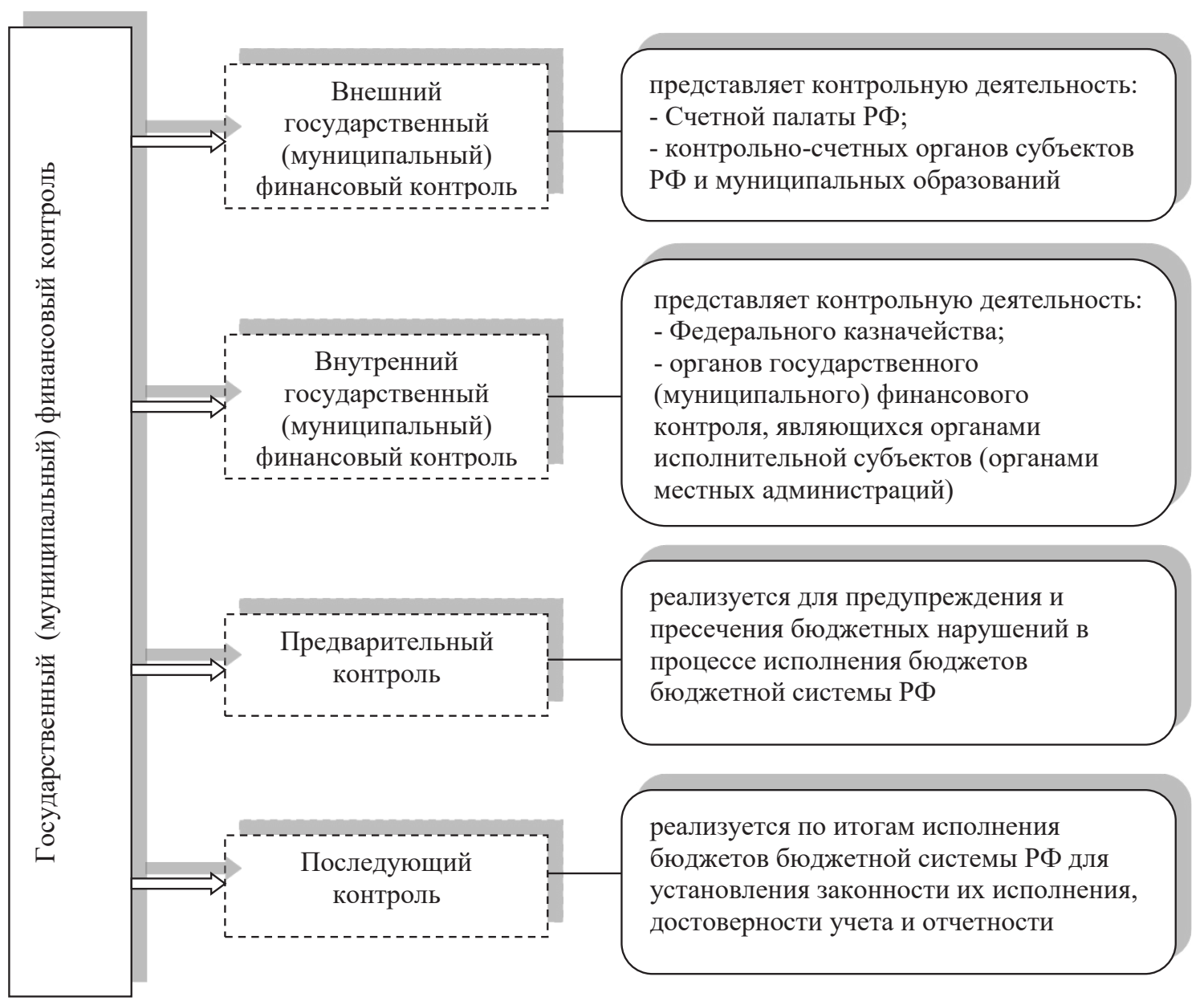

Рис. 4. Виды государственного (муниципального) финансового контроля 
федеральных проектов. Решение данной задачи будет являться основой для выявления финансового мошенничества, правонарушений, отрицательного влияния факторов на достижение целей и задач проектов.

K четвертой задаче относится создание эффективного механизма финансового контроля, без которого невозможно своевременное и объективное реагирование уполномоченных надзорных и контрольных органов на выявленные отрицательные отклонения или нарушения.

Пятая задача посвящена совершенствованию инструментария оперативного и превентивного инструментария реализации финансового контроля в рамках расходования средств на федеральные проекты.

Негосударственный финансовый контроль включает независимый финансовый контроль (аудит), общественный контроль и внутренний финансовый контроль организаций (рисунок 5).

Правительство Российской Федерации продолжает разрабатывать меры, направленные на совершенствование механизма финансового контроля, в первую очередь ориентированного на рациональное использование и расходование бюджетных средств в рамках бюджетного процесса.

В БК РФ регламентируются понятия и основные характеристики по формированию и расходованию бюджетных средств в рамках бюджетного процесса. В частности, глава 29 посвящена общим положениям о бюджетных нарушениях и применении бюджетных мер принуждения. Статья 306.1 БК РФ гласит, что «бюджетным нарушением признается совершенное высшим исполнительным органом государственной власти субъекта Российской Федерации (местной администрацией), финансовым органом, главным администратором (администратором) бюджетных средств, государственным (муниципальным) заказчиком:

1) нарушение положений бюджетного законодательства Российской Федерации и иных правовых актов, регулирующих бюджетные правоотношения;

2) нарушение положений правовых актов, обусловливающих публичные нормативные обязательства и обязательства по иным выплатам физическим лицам из бюджетов бюджетной системы Российской Федерации, повлекшее причинение ущерба публично-правовому образованию;

3) нарушение условий договоров (соглашений) о предоставлении средств из бюджета;

4) нарушение установленных законодательством Российской Федерации о контрактной системе в сфере закупок товаров, работ, услуг для обеспечения государственных (муниципальных) нужд требований к планированию, обоснованию закупок товаров, работ, услуг для обеспечения государственных (муниципальных) нужд, а также требований к изменению, расторжению государственного (муниципального) контракта;

5) нарушение условий государственных (муниципальных) контрактов;

6) нарушение условий договоров (соглашений), заключенных в целях исполнения договоров (соглашений) о предоставлении средств из бюджета, повлекшее причинение ущерба публично-правовому образованию;

7) несоблюдение целей, порядка и условий

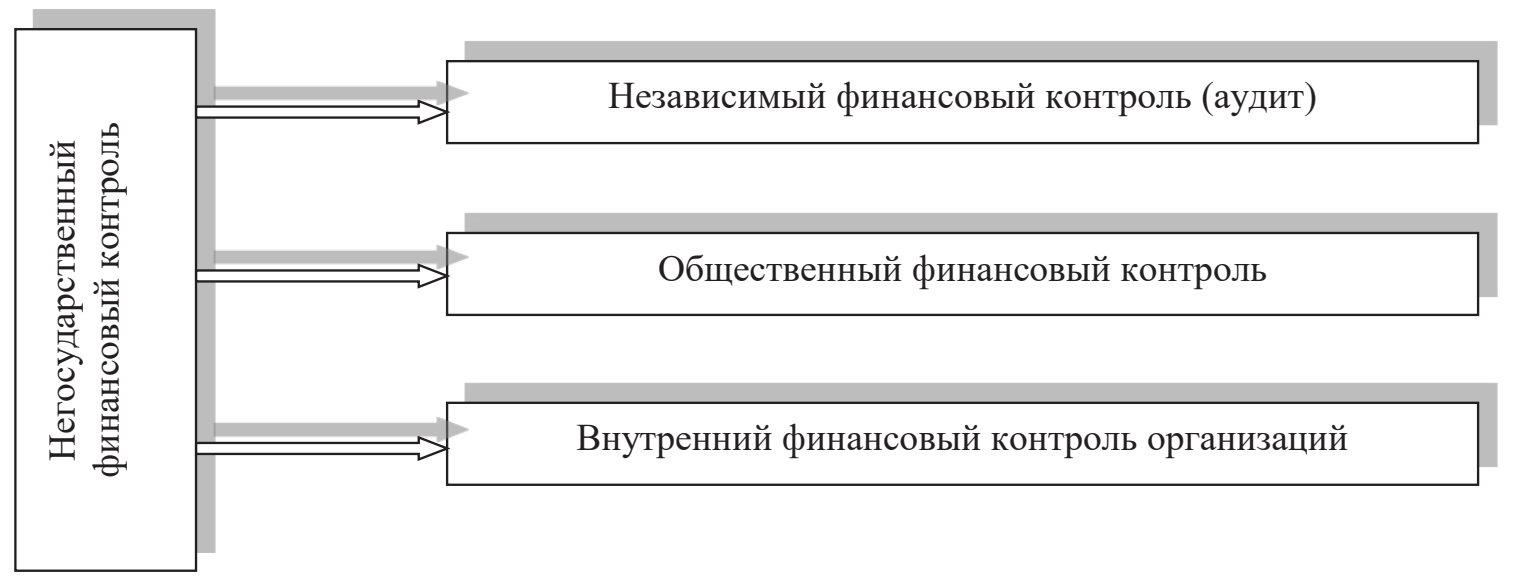

Рис. 5. Виды негосударственного финансового контроля 
предоставления кредитов, обеспеченных государственными и муниципальными гарантиями» [3].

Статьей 285.1 Уголовного кодекса Российской Федерации вменяется ответственность за нецелевое расходование бюджетных средств [4]. Согласно данной статьи вменяется наказание за «расходование бюджетных средств должностным лицом получателя бюджетных средств на цели, не соответствующие условиям их получения, определенным утвержденными бюджетом, бюджетной росписью, уведомлением о бюджетных ассигнованиях, сметой доходов и расходов либо иным документом, являющимся основанием для получения бюджетных средств» [4].

Кодекс Российской Федерации об административных правонарушениях (КоАП РФ) также закрепляет административную ответственность за правонарушения в области бюджетного процесса. Согласно статьи 15.14 КоАП РФ вменяется административная ответственность за «нецелевое использование бюджетных средств, выразившееся в направлении средств бюджета бюджетной системы Российской Федерации и оплате денежных обязательств в целях, не соответствующих полностью или частично целям, определенным законом (решением) о бюджете, сводной бюджетной росписью, бюджетной росписью, бюджетной сметой, договором (соглашением) либо иным документом, являющимся правовым основанием предоставления указанных средств, или в направлении средств, полученных из бюджета бюджетной системы Российской Федерации, на цели, не соответствующие целям, определенным договором (соглашением) либо иным документом, являющимся правовым основанием предоставления указанных средств, если такое действие не содержит уголовно наказуемого деяния» [5].

Федеральный закон от 05.04.2013 г. № 44-Ф3 «О контрактной системе в сфере закупок товаров, работ, услуг для обеспечения государственных и муниципальных нужд» [6] в целях усиления мер государственного финансового контроля использования бюджетных ресурсов обязывает размещать расширенную информацию о государственных контрактах и их исполнении на сайте www.zakupki.gov.ru. В данной системе размещается не только конкурсная документация по государственным контрактам, планы закупок и их обоснование, но и результаты конкурса, а также акты выполненных работ (оказанных ус- луг) и т.п.

Таким образом, «в целях информационного обеспечения контрактной системы в сфере закупок ведется единая информационная система, взаимодействие которой с иными информационными системами обеспечивает:

1) формирование, обработку, хранение и предоставление данных (в том числе автоматизированные) участникам контрактной системы в сфере закупок;

2) контроль за соответствием:

a) информации об объеме финансового обеспечения, включенной в планы закупок, информации об объеме финансового обеспечения для осуществления закупок, утвержденном и доведенном до заказчика;

б) информации, включенной в планыграфики закупок (далее также-планы-графики), информации, содержащейся в планах закупок;

в) информации, содержащейся в извещениях об осуществлении закупок, в документации о закупках, информации, содержащейся в планах-графиках;

г) информации, содержащейся в протоколах определения поставщиков (подрядчиков, исполнителей), информации, содержащейся в документации о закупках;

д) условий проекта контракта, направляемого в форме электронного документа участнику закупки, с которым заключается контракт, информации, содержащейся в протоколе определения поставщика (подрядчика, исполнителя);

е) информации о контракте, включенной в реестр контрактов, заключенных заказчиками, условиям контракта;

3) использование усиленной квалифицированной электронной подписи для подписания электронных документов» [6].

Подводя итог вышеуказанному, необходимо отметить, что ответственность за правонарушения в области бюджетного процесса закрепляется:

- ст. 306.4 БК РФ;

- ст. 285.1; 285.2 УК РФ;

- ст. 15.14 КоАП РФ.

В повышении эффективности государственного контроля ключевую роль играет внутренний финансовый контроль. В этой связи Правительство Российской Федерации также вносит поправки в нормативные документы, совершенствующие систему государственного контроля. 
К одному из таких документов относится Федеральный закон от 26.07.2019 № 199-ФЗ «О внесении изменений в Бюджетный кодекс Российской Федерации в части совершенствования государственного (муниципального) финансового контроля, внутреннего финансового контроля и внутреннего финансового аудита» [7].

Необходимо отметить, что для повышения эффективности и установления законности исполнения федеральных проектов и расходования на них средств, реализация внутреннего контроля должна опираться на оперативный и превентивный инструментарий.

Каждый этап работы с федеральными проектами от момента планирования до его завершения требует детальной проверки. Это подтверждает необходимость разработки действенного оперативного и превентивного инструментария внутреннего финансового контроля в рамках расходования средств на федеральные проекты с позиции распределителей бюджетных средств.

Оперативный внутренний финансовый контроль в рамках расходования средств на федеральные проекты следует рассматривать как регламентированную локальными документами организации деятельность по проверке операций, связанных с реализацией данных проектов, как в целом предприятия, так и отдельных его подразделений. Такой контроль необходим для органов управления как в деятельности распределителей бюджетных средств, так и их получателей. Именно оперативный внутренний контроль формирует полную картину происходящего в рамках реализации федеральных проектов, позволяет объективно оценить законность операций по расходованию бюджетных средств, их целевое назначение, рациональность и соответствие условиям контрактов.

К основным видам процедур превентивного контроля в рамках расходования средств на федеральные проекты следует отнести:

- авторизацию - предусматривающую, что любая трансакция осуществляется по результатам физической авторизации;

- управление доступом - предполагающую ограничение доступа к учетным данным и сведениям внутренней управленческой отчетности;

- разделение полномочий - представляющую собой функциональное разделение по ав- торизации и физического проведения трансакции;

- проверку соответствия - предполагающую определение соответствия проводимых действий, трансакций законодательству, целевой направленности, условиям контракта;

- оценку рисков - предусматривающую анализ и оценку рисков с целью предупреждения возможных негативных последствий.

Превентивные контрольные процедуры направлены на предотвращение наступления нежелательных последствий, снижение рисков не достижения целей посредством превентивных процедур, которое достигается запретом нежелательных, недопустимых действий до их совершения.

В процессе реализации оперативного финансового контроля в рамках расходования бюджетных средств на федеральные проекты необходимо выполнять следующие действия:

- определять фактическое состояние выполнения проектов;

- сравнивать фактические суммы расходов, связанных с выполнением федеральных проектов с планируемыми;

- оценивать отклонения, превышающие предельно допустимый уровень и выявлять их причины;

- проверять правильность оформления всей документации, связанной с операциями по выполнению федеральных проектов и расходованию бюджетных средств;

- выносить предложения по оптимизации деятельности, связанной с федеральными проектами;

- контролировать исполнения мер по устранению выявленных отклонений и нарушений.

С целью развития инструментария разработаем основные процедуры превентивного и оперативного внутреннего финансового контроля в рамках расходования средств на федеральные проекты для распределителей средств и представим их в таблице 1.

Таким образом, основная цель внутреннего финансового контроля для распорядителей средств на федеральные проекты - это контроль за выполнением федеральных проектов от этапа планирования до этапа его завершения. При этом превентивный внутренний финансовый контроль позволяет предупредить возможные негативные последствия ошибок и нарушений 
Таблица 1. Основные процедуры превентивного и оперативного внутреннего финансового контроля в рамках расходования средств на федеральные проекты для распределителей средств

\begin{tabular}{|c|c|c|}
\hline № п/п & $\begin{array}{c}\text { Вид внутреннего } \\
\text { финансового контроля }\end{array}$ & Перечень контрольных процедур \\
\hline 1 & 2 & 3 \\
\hline 1 & $\begin{array}{l}\text { Превентивный внутренний } \\
\text { финансовый контроль }\end{array}$ & $\begin{array}{l}\text { Проверка прогноза макроэкономических показателей, исходных для } \\
\text { составления федерального проекта }\end{array}$ \\
\hline 2 & $\begin{array}{l}\text { Превентивный внутренний } \\
\text { финансовый контроль }\end{array}$ & $\begin{array}{l}\text { Проверка качества прогноза социально-экономического эффекта по } \\
\text { результатам выполнения федерального проекта }\end{array}$ \\
\hline 3 & $\begin{array}{l}\text { Превентивный внутренний } \\
\text { финансовый контроль }\end{array}$ & $\begin{array}{l}\text { Проверка соответствия предмета федерального проекта прогнозу } \\
\text { социально-экономического развития и статьям федерального бюд- } \\
\text { жета }\end{array}$ \\
\hline 4 & $\begin{array}{l}\text { Превентивный внутренний } \\
\text { финансовый контроль }\end{array}$ & Проверка качества составления требований к федеральному проекту \\
\hline 5 & $\begin{array}{l}\text { Превентивный внутренний } \\
\text { финансовый контроль }\end{array}$ & Проверка прогноза расходов по федеральному проекту \\
\hline 6 & $\begin{array}{l}\text { Превентивный внутренний } \\
\text { финансовый контроль }\end{array}$ & Проверка обоснованности показателей федерального проекта \\
\hline 7 & $\begin{array}{l}\text { Превентивный внутренний } \\
\text { финансовый контроль }\end{array}$ & $\begin{array}{l}\text { Проверка полноты отражения, обоснованности и достоверности } \\
\text { планируемых расходов по федеральному проекту }\end{array}$ \\
\hline 8 & $\begin{array}{l}\text { Превентивный внутренний } \\
\text { финансовый контроль }\end{array}$ & $\begin{array}{l}\text { Проверка условий и требований федеральных проектов на соответ- } \\
\text { ствие требованием программ развития }\end{array}$ \\
\hline 9 & $\begin{array}{l}\text { Превентивный внутренний } \\
\text { финансовый контроль }\end{array}$ & $\begin{array}{l}\text { Проверка согласования всей документации по выделению средств по } \\
\text { федеральным проектам }\end{array}$ \\
\hline 10 & $\begin{array}{l}\text { Оперативный внутренний } \\
\text { финансовый контроль }\end{array}$ & $\begin{array}{l}\text { Проверка расходных денежных документов (расчетно-платежных } \\
\text { ведомостей, платежных поручений, банковских выписок, счетов на } \\
\text { оплату) по федеральному проекту }\end{array}$ \\
\hline 11 & $\begin{array}{l}\text { Оперативный внутренний } \\
\text { финансовый контроль }\end{array}$ & $\begin{array}{l}\text { Проверка правильности заполнения финансовых документов, } \\
\text { наличия подписей ответственных лиц, наличия заполненных всех } \\
\text { обязательных реквизитов }\end{array}$ \\
\hline 12 & $\begin{array}{l}\text { Оперативный внутренний } \\
\text { финансовый контроль }\end{array}$ & $\begin{array}{l}\text { Проверка обоснованности произведенных расходов по федеральным } \\
\text { проектам }\end{array}$ \\
\hline 13 & $\begin{array}{l}\text { Оперативный внутренний } \\
\text { финансовый контроль }\end{array}$ & $\begin{array}{l}\text { Проверка целевой направленности произведенных расходов соглас- } \\
\text { но федеральным проектам }\end{array}$ \\
\hline 14 & $\begin{array}{l}\text { Оперативный внутренний } \\
\text { финансовый контроль }\end{array}$ & Проверка отчетной документации по федеральным проектам \\
\hline 15 & $\begin{array}{l}\text { Оперативный внутренний } \\
\text { финансовый контроль }\end{array}$ & $\begin{array}{l}\text { Проверка выполнения федеральных проектов согласно установлен- } \\
\text { ным графикам и этапам }\end{array}$ \\
\hline 16 & $\begin{array}{l}\text { Оперативный внутренний } \\
\text { финансовый контроль }\end{array}$ & $\begin{array}{l}\text { Проверка движения денежных средств в рамках исполнения феде- } \\
\text { ральных проектов }\end{array}$ \\
\hline
\end{tabular}

и не допустить их наступления в будущем. Оперативный внутренний финансовый направлен на проверку от этапа финансирования до этапа завершения федерального проекта и позволяет оперативно выявить текущие нарушения с целью их своевременного устранения.

Для развития инструментария разработаем основные процедуры превентивного и оперативного внутреннего финансового контроля в рамках расходования средств на федеральные проекты для получателей средств и представим их в таблице 2 .

На основании вышеизложенного следует, что ключевой целью внутреннего финансового контроля для получателей средств на федеральные проекты является проверка выполнения федеральных проектов от этапа участия до этапа его завершения. При этом превентивный внутренний финансовый контроль направлен на предупреждение возможных рисков и отрицательных последствий нарушений. Оперативный внутренний финансовый осуществляется от этапа получения финансирования до этапа завершения федерального проекта и позволяет своевременно пресечь выявленные нарушения. 
Таблица 2. Основные процедуры превентивного и оперативного внутреннего финансового контроля в рамках расходования средств на федеральные проекты для получателей средств

\begin{tabular}{|c|c|c|}
\hline № $\Pi / \Pi$ & $\begin{array}{c}\text { Вид внутреннего } \\
\text { финансового контроля }\end{array}$ & Перечень контрольных процедур \\
\hline 1 & 2 & 3 \\
\hline 1 & $\begin{array}{l}\text { Превентивный внутренний } \\
\text { финансовый контроль }\end{array}$ & $\begin{array}{l}\text { Проверка финансово-плановой документации (расчета потребности } \\
\text { в средствах, плана выполнения федеральных проектов, продолжи- } \\
\text { тельности федеральных проектов и др.) }\end{array}$ \\
\hline 2 & $\begin{array}{l}\text { Превентивный внутренний } \\
\text { финансовый контроль }\end{array}$ & $\begin{array}{l}\text { Проверка достоверности и правильности оформления финансово- } \\
\text { плановых документов на федеральные проекты, их визирование, } \\
\text { согласование и урегулирование разногласий }\end{array}$ \\
\hline 3 & $\begin{array}{l}\text { Превентивный внутренний } \\
\text { финансовый контроль }\end{array}$ & $\begin{array}{l}\text { Проверка и визирование проектов договоров специалистами юри- } \\
\text { дического отдела и главной бухгалтерией (главным бухгалтером) }\end{array}$ \\
\hline 4 & $\begin{array}{l}\text { Превентивный внутренний } \\
\text { финансовый контроль }\end{array}$ & $\begin{array}{l}\text { Предварительная экспертиза документации (решений), связанных с } \\
\text { расходованием финансовых и материальных средств }\end{array}$ \\
\hline 5 & $\begin{array}{l}\text { Превентивный внутренний } \\
\text { финансовый контроль }\end{array}$ & $\begin{array}{l}\text { Проверка согласования всей документации по поступлению средств } \\
\text { по федеральным проектам }\end{array}$ \\
\hline 6 & $\begin{array}{l}\text { Превентивный внутренний } \\
\text { финансовый контроль }\end{array}$ & $\begin{array}{l}\text { Проверка соответствия графиков получения средств условиям кон- } \\
\text { тракта }\end{array}$ \\
\hline 10 & $\begin{array}{l}\text { Оперативный внутренний } \\
\text { финансовый контроль }\end{array}$ & $\begin{array}{l}\text { Проверка расходных и приходных денежных документов (расчетно- } \\
\text { платежных ведомостей, платежных поручений, банковских выписок, } \\
\text { счетов на оплату) }\end{array}$ \\
\hline 11 & $\begin{array}{l}\text { Оперативный внутренний } \\
\text { финансовый контроль }\end{array}$ & $\begin{array}{l}\text { Проверка правильности заполнения финансовых документов, } \\
\text { наличия подписей ответственных лиц, наличия заполненных всех } \\
\text { обязательных реквизитов }\end{array}$ \\
\hline 12 & $\begin{array}{l}\text { Оперативный внутренний } \\
\text { финансовый контроль }\end{array}$ & $\begin{array}{l}\text { Проверка обоснованности произведенных расходов по федераль- } \\
\text { ным проектам }\end{array}$ \\
\hline 13 & $\begin{array}{l}\text { Оперативный внутренний } \\
\text { финансовый контроль }\end{array}$ & $\begin{array}{l}\text { Проверка целевой направленности произведенных расходов соглас- } \\
\text { но федеральным проектам }\end{array}$ \\
\hline 14 & $\begin{array}{l}\text { Оперативный внутренний } \\
\text { финансовый контроль }\end{array}$ & $\begin{array}{l}\text { Сверка данных аналитического учета с синтетическим по счетам, } \\
\text { связанным с расходованием средств по федеральным проектам }\end{array}$ \\
\hline 15 & $\begin{array}{l}\text { Оперативный внутренний } \\
\text { финансовый контроль }\end{array}$ & $\begin{array}{l}\text { Проверка полноты оприходования полученных в банке денежных } \\
\text { средств }\end{array}$ \\
\hline 16 & $\begin{array}{l}\text { Оперативный внутренний } \\
\text { финансовый контроль }\end{array}$ & $\begin{array}{l}\text { Проверка исполнения всех договоров с субподрядчиками и внешни- } \\
\text { ми исполнителями в рамках исполнения федеральных проектов }\end{array}$ \\
\hline 17 & $\begin{array}{l}\text { Оперативный внутренний } \\
\text { финансовый контроль }\end{array}$ & $\begin{array}{l}\text { Проверка расчетов по всем договорам с субподрядчиками и внеш- } \\
\text { ними исполнителями в рамках исполнения федеральных проектов }\end{array}$ \\
\hline 18 & $\begin{array}{l}\text { Оперативный внутренний } \\
\text { финансовый контроль }\end{array}$ & $\begin{array}{l}\text { Проверка движения денежных средств в рамках исполнения феде- } \\
\text { ральных проектов }\end{array}$ \\
\hline 19 & $\begin{array}{l}\text { Оперативный внутренний } \\
\text { финансовый контроль }\end{array}$ & $\begin{array}{l}\text { Проверка правильности начисления и уплату налогов в рамках ис- } \\
\text { полнения федеральных проектов }\end{array}$ \\
\hline 20 & $\begin{array}{l}\text { Оперативный внутренний } \\
\text { финансовый контроль }\end{array}$ & Проверка отчетной документации \\
\hline 21 & $\begin{array}{l}\text { Оперативный внутренний } \\
\text { финансовый контроль }\end{array}$ & $\begin{array}{l}\text { Сверка данных отчетной документации с данными остатков по сче- } \\
\text { там, первичным расходным документам и документам, являющи- } \\
\text { мися основанием для осуществления расходных операций в рамках } \\
\text { исполнения федеральных проектов и др. }\end{array}$ \\
\hline
\end{tabular}

Статья подготовлена в рамках выполнения прикладной научно-исследовательской работы по теме: «Создание системы внутреннего финансового контроля, обладающей возможностями для работы на опережающее устранение предпосылок финансовых нарушений при расходовании средств на федеральные проекты на основе оценки отраслевых рисков» 


\section{Библиографический список}

1. Информация Минфина России № П3-11/2013 «Организация и осуществление экономическим субъектом внутреннего контроля совершаемых фактов хозяйственной жизни, ведения бухгалтерского учета и составления бухгалтерской (финансовой) отчетности».

2. Бюджетный кодекс Российской Федерации от 31.07.1998 № 145-Ф3 (ред. от 27.12.2019 г.).

3. Бюджетный кодекс Российской Федерации от 31.07.1998 № 145-Ф3 (ред. от 27.12.2019 г.).

4. Уголовный кодекс Российской Федерации от 13.06.1996 г. № 63-ФЗ (в ред. 18.02 .2020 г.).

5. Кодекс Российской Федерации об административных правонарушениях от 30.12.2001 № 195-ФЗ (в ред. от 18.02.2020).

6. Федеральный закон от 05.04.2013 г. № 44-Ф3 «О контрактной системе в сфере закупок товаров, работ, услуг для обеспечения государственных и муниципальных нужд» (в ред. от 27.12.2019 г.).

7. Федеральный закон от 26.07.2019 № 199-ФЗ «О внесении изменений в Бюджетный кодекс Российской Федерации в части совершенствования государственного (муниципального) финансового контроля, внутреннего финансового контроля и внутреннего финансового аудита».

8. Бабаев Ю.А., Друцкая М.В., Кеворкова Ж.А., Листопад Е.Е., Петров А. М.Бухгалтерский учет, анализ и аудит внешнеэкономической деятельности / учебник для студентов обучающихся по специальности 080109 «Бухгалтерский учет, анализ и аудит» / под редакцией Ю.А. Бабаева. Москва, 2010.

9. Петров А.М., Мельникова Л.А. Теоретические аспекты учета калькулирования себестоимости продукции / Экономические науки. 2013. № 102. С. 145-148.

10. Kevorkova Z.A., Petrov A.M., Savina N. V. Towards Liabilities Of Corporate Systems / International Journal of Civil Engineering and Technology. 2019. T. 10. № 2. C. 1582-1593.

11. Lymar M.P., Kevorkova Z.A., PetrovA.M. The Convergence Of National And International Accounting Standards: Chinese Experience / International Journal of Civil Engineering and Technology. 2018. T. 9. № 13. C. 82-94.

12. Петров А.М., Коняхин А.Н. Учетная политика при подготовке первой отчетности согласно МСФО / Международный бухгалтерский учет. 2013. № 11 (257). С. 2-15. 